\title{
INVESTIMENTO EM DEFESA E ECONOMIA: UM ESTUDO SOBRE A RELAÇÃO DE CAUSALIDADE
}

\author{
Rodrigo Halfeld \\ Pontifícia Universidade Católica do Rio de Janeiro - PUC-Rio \\ R. Marquês de São Vicente, 225 - Gávea, Rio de Janeiro - RJ, 22451-900 \\ rodhalfeld@hotmail.com \\ Marcela Cohen Martelotte \\ Universidade Federal Fluminense - UFF/EEIMVR \\ Av. dos Trabalhadores 420 - Vila Sta. Cecília, Volta Redonda - RJ, 27255-125 \\ marcelacohen@id.uff.br \\ Carlos Bastian Pinto \\ Pontifícia Universidade Católica do Rio de Janeiro - PUC-Rio \\ R. Marquês de São Vicente, 225 - Gávea, Rio de Janeiro - RJ, 22451-900 \\ carbastian@gmail.com
}

\begin{abstract}
RESUMO
O efeito do investimento em defesa na economia é tema de diversos debates, havendo defensores e críticos. Este trabalho investiga a relação entre o investimento em defesa e a economia, utilizando o teste de causalidade de Granger. Para isso, são analisados os dados de investimento em defesa, produto interno bruto e formação bruta de capital fixo de seis países. São eles: Brasil, China, Estados Unidos da América, França, Reino Unido e Rússia. Os resultados indicam relação de causalidade (no sentido de Granger) em alguns desses países.
\end{abstract}

Palavra-chave: Investimento em Defesa; Produto Interno Bruto; Formação Bruta de Capital Fixo; Teste de Causalidade de Granger.

\begin{abstract}
The effect of defense expenditure on economic growth is the subject of many debates. This study investigates the relationship between defense expenditure and economic growth applying Granger causality test. In order to do this, data of military expenditure, gross domestic product and gross capital formation from six countries are analyzed. They are: Brazil, China, United States of America, France, United Kingdom and Russia. The findings of the study indicate Granger causality relationship for some of these countries.
\end{abstract}

Keywords: Defense Investment; Gross Domestic Product; Gross Capital Formation; Granger Causality Test. 


\section{Como Citar:}

HALFELD, Rodrigo; MARTELOTTE, Marcela Cohen; SOUZA, Reinaldo Castro. Investimento em defesa e economia: um estudo sobre a relação de causalidade. In: SIMPÓSIO DE PESQUISA OPERACIONAL E LOGÍSTICA DA MARINHA, 19., 2019, Rio de Janeiro, RJ. Anais [...]. Rio de Janeiro: Centro de Análises de Sistemas Navais, 2019.

\section{INTRODUÇÃO}

Em momentos de crise financeira, debates sobre quais setores devem sofrer cortes e quais devem receber aumentos assumem as principais pautas dos governos e mídia. Com o investimento em defesa não é diferente, sendo uma temática debatida ao longo da história das civilizações, por um lado estudada como um instrumento de desenvolvimento e algo basilar para o funcionamento soberano de um país, e por outro lado, como uma forma de mecanismo de opressão e de reação ao progresso.

Observando este embate, diversos pesquisadores dedicaram estudos para analisar o efeito do investimento em defesa na economia. Tahir e Sajid (1999) aplicaram o teste de causalidade de Granger para analisar como o investimento em defesa tem relação com a economia paquistanesa e de outros países subdesenvolvidos; nesse estudo, eles observaram uma relação de causalidade entre ambas as variáveis. Al-Yousif (2002) pesquisou o impacto do investimento em defesa em seis países do Golfo Arábico; com base no teste de causalidade de Granger, foi constatada relação entre investimento em defesa e economia. Tambudzai (2007) adotou a metodologia de dados em painel em uma amostra de 12 países africanos, na qual observou que o investimento em defesa foi um fardo para os países, uma vez que o investimento não trouxe crescimento econômico, e esse capital poderia ter sido utilizado em outros setores como o da saúde. Ando (2009) realizou um teste de causalidade com uma amostra de 109 países, onde observou que o investimento em defesa influencia positivamente na economia, ajudando-a a crescer. Wang et al. (2012) estudaram o impacto do investimento em defesa na economia dos países da Organização para a Cooperação e o Desenvolvimento Econômico (OECD); os resultados mostraram que as estratégias efetivas de investimento em defesa são importantes para melhorar a economia desses países. Gokmenoglu et al. (2015) aplicaram o teste de causalidade de Granger para examinar a relação entre investimento em defesa e crescimento econômico na Turquia; os resultados indicaram a existência de uma relação unilateral do crescimento econômico para o investimento em defesa.

O objetivo deste artigo é analisar por meio de teste de causalidade de Granger o impacto do investimento em defesa na economia. A análise será realizada para seis países: Brasil, China, Estados Unidos da América (EUA), França, Reino Unido e Rússia; com base em três variáveis: investimento em defesa, produto interno bruto (PIB) e formação bruta de capital fixo.

Visando elucidar as questões de pesquisa, este artigo está estruturado em seis seções, incluindo a seção introdutória, onde é apresentado o enfoque central. A seção 2 aborda a questão do investimento em defesa, enquanto que a seção 3 traz uma breve discussão sobre a relação entre investimento em defesa e crescimento econômico. Na seção 4 é apresentada a metodologia adotada neste estudo, e a seção 5 mostra a análise de resultados obtidos. Por fim, na seção 6 são apresentadas as considerações finais. 


\section{O INVESTIMENTO EM DEFESA}

A existência de um orçamento para a defesa é algo obrigatório para a maioria dos países. Infelizmente, a história da humanidade faz com que o tema nunca saia de pauta somente no século XX o mundo assistiu a duas guerras mundiais, dezenas de guerras civis como as da China, Coreia e Vietnam, guerras coloniais e de independência, como a da Irlanda. Tudo isso sem contar o temor global gerado pela guerra fria, que ao seu fim passou a ideia de que o mundo finalmente viveria em paz.

Como mostrado nos Gráficos 1 e 2, algumas das principais potências, como Estados Unidos da América, França e Reino Unido, estavam diminuindo o investimento em defesa quando houve o ataque do dia 11 de setembro de 2001. A partir dessa data um novo tipo de guerra foi criado, a "guerra ao terror". Nessa guerra, novos ataques são planejados e executados em diversos países, dando a impressão de que nenhum país está a salvo das ações de radicais facilmente travestidos de inocentes civis.

Gráfico 1. Investimento em Defesa (\% do PIB) de 1992 a 2017: Brasil, China, França e Reino Unido (UK)

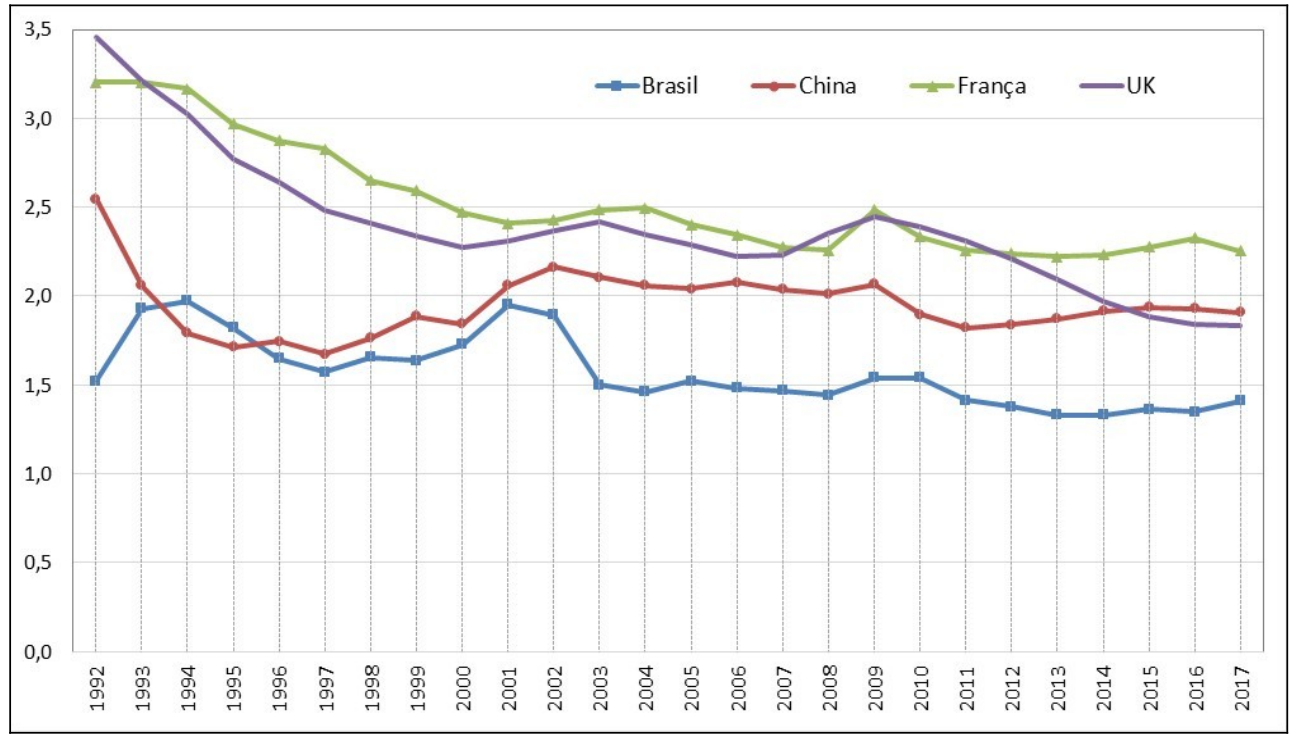

Fonte: THE WORLD BANK, 2019.

Gráfico 2. Investimento em Defesa (\% do PIB) de 1992 a 2017: Rússia e EUA

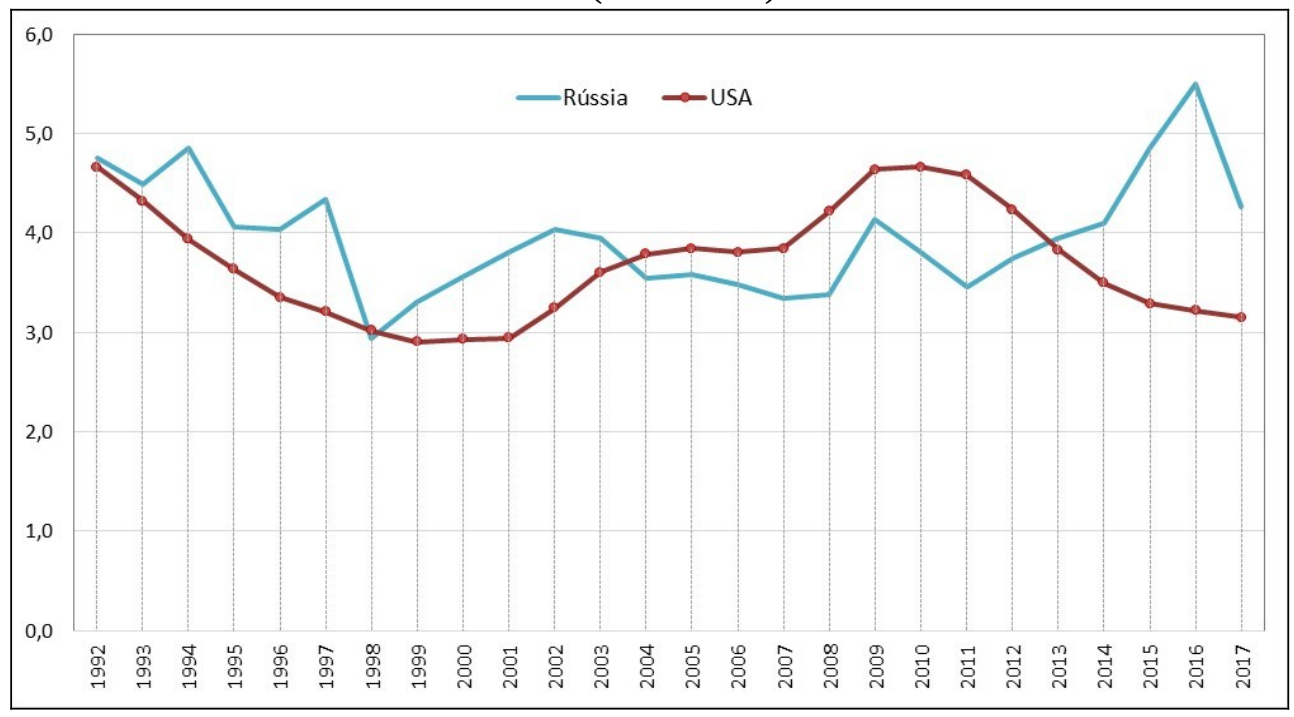


Fonte: THE WORLD BANK, 2019.

Além da justificativa moderna do investimento em defesa, há uma explicação histórica para cada país que tem seu ideal apoiado em algum grande pensador do passado. China e Rússia sofreram constantemente com invasões estrangeiras ao longo da história, guerras que geraram muito sofrimento para o povo e nação. Com este histórico é compreensível que eles tenham uma visão muito pessimista do mundo, uma visão semelhante à de Hobbes (1651), que acreditava que um estado deveria ser forte para evitar o pior do ser humano.

Apesar dos EUA, Reino Unido e França também terem sofrido com invasões, e considerando o fato desses países terem cometidos grande parte das invasões ao longo dos últimos séculos, uma adoção da filosofia de Hobbes (1651) não explica o seu investimento em defesa. Esses países têm em seu cerne a luta pela liberdade e a importância de sua manutenção. Seja uma liberdade cultural ou stricto sensu, é natural ver discursos de políticos e de civis enaltecendo a importância de uma população que saiba lutar contra um inimigo externo ou interno. Sendo assim, a filosofia de Maquiavel (1532) é a que melhor explica o motivo de um grande investimento em defesa nos tempos atuais. Porém, baseando-se na história, a filosofia de Maquiavel (1532) não é a única empregada por esses três países. Ao longo de suas existências, EUA, Reino Unido e França invadiram territórios que não os pertenciam, apenas com o intuito de conseguir uma vantagem estratégica, seja militar, comercial ou expansionista. Sendo assim, pode-se afirmar que a filosofia de Von Clausewitz (1832) foi bem aceita por tomadores de decisão.

Ao contrário dos outros países analisados neste trabalho, o Brasil é o único do grupo que não é considerado uma potência militar e que sofreu, ao longo de um século, diversas mudanças radicais de regime governamental, o que dificulta encontrar uma linha de pensamento que explique o investimento em defesa por parte do governo brasileiro.

\section{INVESTIMENTO EM DEFESA E CRESCIMENTO ECONÔMICO}

A economia de defesa tem seus fundamentos na teoria econômica de Keynes (1936), a qual diz que os gastos do governo podem impactar a economia como um todo de forma positiva através do efeito de demanda agregada. A curva de demanda agregada nos diz a quantidade de todos os bens e serviços demandados na economia, a qualquer nível de preço dado. Essa curva pode ser deslocada/manipulada de acordo com a vontade do governo e a necessidade do mercado. O governo pode influenciar o comportamento da economia por meio da política monetária e fiscal, que compreende as escolhas do governo quanto ao nível geral de compras governamentais ou aos impostos.

Quando os formuladores de políticas alteram suas próprias compras de bens e serviços, o deslocamento da curva de demanda agregada é direto. Quando o governo decide adquirir veículos de transporte como ônibus, caminhões e carros de passeio, por exemplo, ele eleva a produção dos fabricantes, induzindo as empresas a contratar mais empregados e a aumentar a produção. $\mathrm{O}$ aumento na demanda por esses veículos significa um aumento na quantidade total de bens e serviços demandada a qualquer nível de preços. Como efeito, a curva de demanda agregada se desloca.

É na tentativa de quantificar o deslocamento, que se percebe o efeito desejado por Keynes, pois a princípio a resposta para a questão seria que o deslocamento é igual ao gasto feito pelo governo. Porém, há dois efeitos macroeconômicos que fazem com que o deslocamento da curva seja diferente do desembolso do governo: o primeiro é o efeito multiplicador, que sugere que o deslocamento seja superior ao que o governo gastou ao adquirir os veículos; o segundo é o efeito deslocamento, que sugere que o deslocamento seja inferior ao desembolso do governo. 
O conceito do primeiro efeito macroeconômico (efeito multiplicador) está baseado na ideia de que quando o governo gasta para adquirir algo como veículos, essa compra tem repercussões. Uma delas é que as empresas que ganharam os contratos terão lucros maiores e irão empregar mais. Assim, haverá menos desempregados, a renda média aumentará e por fim estes irão consumir mais bens de consumo e serviços. Como resultado, essa compra do governo não só terá elevado a demanda de veículos, como também aumentado a demanda de vários outros produtos e serviços.

Esse efeito multiplicador continua mesmo depois dessa primeira rodada. Quando as despesas de consumo aumentam, as empresas que produzem esses bens contratam mais pessoas e registram maiores lucros. Os maiores salários e lucros estimulam novamente as despesas de consumo, e assim por diante. Portanto, há uma resposta positiva na medida em que maior demanda leva a maior renda que, por sua vez, leva a uma demanda ainda mais elevada. Uma vez somados todos esses efeitos, o impacto total sobre a quantidade de bens e serviços demandada pode ser muito maior do que o impulso inicial decorrente das maiores despesas do governo (MANKIW, 2008).

Para calcular a magnitude do multiplicador de despesas, é importante considerar o conceito da propensão marginal a consumir (PMgC), que é a fração da renda que um agente econômico (indivíduo, família ou empresa) consome ao invés de poupar, ao receber uma unidade de renda adicional. Para exemplificar, se a propensão marginal a consumir for $3 / 4$, para cada real adicional percebido pelo agente econômico, 3/4 serão gastos, isto é, reinseridos na economia.

\section{METODOLOGIA}

\subsection{Teste de Causalidade de Granger}

O teste de causalidade de Granger, proposto por Clive Granger (1969), é um teste de hipótese que analisa a precedência temporal entre variáveis. O princípio do teste indica que se valores presentes ou passados da variável $X$ ajudam a prever os valores futuros da variável Y, é dito que X Granger-causa Y. É importante notar que a afirmação "X Grangercausa Y” não implica que Y é resultado de X; a causalidade de Granger mede a precedência da informação, mas não indica causalidade no sentido comum do termo.

A base matemática do teste se dá conforme demonstrado nas fórmulas a seguir (GRANGER, 1969):

$$
\begin{aligned}
& X(t)=\sum_{j=1}^{l} a_{j} X(t-j)+\sum_{j=1}^{l} b_{j} Y(t-j)+\varepsilon_{t} \\
& Y(t)=\sum_{j=1}^{l} c_{j} X(t-j)+\sum_{j=1}^{l} d_{j} Y(t-j)+\eta_{t}
\end{aligned}
$$

onde $l$ é o número máximo de lags; a, b, c e d são os coeficientes do modelo; $\varepsilon_{t}$ e $\eta_{t}$ são ruídos brancos.

A Equação 4.1 indica que valores correntes da variável $\mathrm{X}$ estão relacionados a valores passados da própria variável $\mathrm{X}$, assim como os valores passados da variável $\mathrm{Y}$; a Equação 4.2 indica o mesmo para a variável Y (Carneiro, 2015).

As hipóteses nulas do teste de Causalidade de Granger são as seguintes:

- $\mathrm{H}_{0}$ : X não é causado (no sentido de Granger) por Y.

Caso essa hipótese seja rejeitada, há indícios de que a variável Y Grangercausa $\mathrm{X}$.

- $\mathrm{H}_{0}$ : Y não é causado (no sentido de Granger) por $\mathrm{X}$.

Caso essa hipótese seja rejeitada, há indícios de que a variável X Grangercausa Y. 
Quando ambas as hipóteses nulas são rejeitadas, conclui-se que existe causalidade em ambas as direções, também chamada de causalidade bidirecional. Além disso, quando ambas as hipóteses nulas não são rejeitadas, diz-se que as variáveis são independentes ou, em outras palavras, não são relacionadas casualmente no sentido de Granger.

\subsection{Países Analisados, Variáveis e Hipóteses do Estudo}

Como o objetivo deste estudo é analisar o impacto do investimento em defesa na economia, os países selecionados para a análise são os mais desenvolvidos economicamente e que, ao mesmo tempo, são fortes militarmente. Considerando esses critérios, os membros permanentes do Conselho de Segurança da Organização das Nações Unidas se enquadram perfeitamente. São eles: Estados Unidos da América, China, Reino Unido, França e Rússia. Eles ocupam respectivamente as seguintes posições no que tange ao PIB (dados do ano de 2017): $1^{\mathrm{a}}, 2^{\mathrm{a}}, 6^{\mathrm{a}}, 7^{\mathrm{a}}$ e $11^{\mathrm{a}}$ (THE WORLD BANK, 2019); e as seguintes posições em relação ao investimento em defesa (dados do ano de 2018): $1^{\mathrm{a}}, 2^{\mathrm{a}}, 7^{\mathrm{a}}, 5^{\mathrm{a}}$ e $6^{\mathrm{a}}$ (STOCKHOLM INTERNATIONAL PEACE RESEARCH INSTITUTE, 2019). Além desses cinco países, o Brasil também foi incluído na análise.

As variáveis escolhidas para este estudo foram o produto interno bruto (PIB), a formação bruta de capital fixo (FBCF) e o investimento em defesa.

- O PIB é um dos principais indicadores de desenvolvimento econômico de um país. O seu percentual de crescimento é calculado com base nos preços de mercado em moeda local, mostrando o andamento da economia e sua direção. Muitos acadêmicos também o utilizam para quantificar o padrão de vida de uma população, pois acreditam haver uma forte relação entre crescimento econômico e políticas públicas (ANWAR et al., 2012).

- A formação bruta de capital fixo é considerada um bom indicador da capacidade de produção de uma economia, pois é composta pelos níveis de inventários, melhorias em terrenos, maquinário, construções de escolas, hospitais, ferrovias, estradas, indústrias, salas comerciais e residências particulares.

- O investimento em defesa é calculado pelo orçamento destinado aos departamentos ou ministérios responsáveis pela defesa de um país, e inclui os gastos com pessoal, pesquisa e desenvolvimento, operações militares e aquisições. Não inclui os gastos relacionados à destruição ou conversão de armamentos (ANWAR et al., 2012).

Neste estudo o período considerado para a análise dessas variáveis foi de 1992 a 2017. Tais dados têm periodicidade anual, obtidos no website do Banco Mundial (THE WORLD BANK, 2019). O PIB será considerado em termos de variação anual percentual, e o investimento em defesa, assim como a formação bruta de capital fixo, serão analisados em termos de percentual do PIB.

As hipóteses deste estudo, relacionadas ao teste de causalidade de Granger para cada um dos seis países, são as seguintes:

$\mathrm{H}_{1}$ : Investimento em defesa é causado (no sentido de Granger) pelo PIB.

$\mathrm{H}_{2}$ : PIB é causado (no sentido de Granger) pelo investimento em defesa.

$\mathrm{H}_{3}$ : Investimento em Defesa é causado (no sentido de Granger) pela formação bruta de capital fixo.

$\mathrm{H}_{4}$ : Formação bruta de capital fixo é causada (no sentido de Granger) pelo investimento em defesa.

Na próxima seção estão apresentadas as etapas envolvidas na realização do teste de 
causalidade, assim como os resultados das hipóteses do estudo.

\section{ANÁLISE DE RESULTADOS}

Para a análise dos dados, o primeiro passo consistiu em verificar a ordem de integração de cada variável individualmente, com base no teste de raiz unitária DickeyFuller Aumentado (ADF) (DICKEY e FULLER, 1979 e 1981). Os resultados estão apresentados na Tabela 1, onde foi constatado que a hipótese nula de que a série possui raiz unitária foi rejeitada, ao nível de significância de 5\%, apenas para as seguintes séries: Investimento em Defesa da China e dos EUA; FBCF da Rússia; PIB do Brasil, da França, do Reino Unido e da Rússia. Sendo assim, assume-se que essas séries são estacionárias em nível. As demais séries são integradas de ordem 1 (não-estacionárias em nível, e estacionárias em primeira diferença), com exceção da Investimento em Defesa do Reino Unido que é integrada de ordem 2 (estacionária em segunda diferença).

Tabela 1. Testes de raiz unitária para as variáveis utilizadas no estudo, por país.

\begin{tabular}{|c|c|c|c|c|}
\hline \multirow{2}{*}{ País } & \multirow{2}{*}{ Variável } & \multicolumn{3}{|c|}{$\begin{array}{c}\text { Valor-p do teste de raiz unitária } \\
\text { ADF } \\
\end{array}$} \\
\hline & & $\begin{array}{c}\begin{array}{c}\text { Série em } \\
\text { nível }\end{array} \\
\end{array}$ & $\begin{array}{l}\text { Série em 1 } \\
\text { diferença }\end{array}$ & $\begin{array}{r}\begin{array}{r}\text { Série em 2a } \\
\text { diferença }\end{array} \\
\end{array}$ \\
\hline \multirow{3}{*}{ Brasil } & Investimento em Defesa (\% do PIB) & 0,410 & 0,002 & --- \\
\hline & Formação Bruta de Capital Fixo (\% do PIB) & 0,272 & 0,000 & --- \\
\hline & PIB (\% de crescimento anual) & 0,012 & --- & --- \\
\hline \multirow{3}{*}{ China } & Investimento em Defesa (\% do PIB) & 0,002 & --- & --- \\
\hline & Formação Bruta de Capital Fixo (\% do PIB) & 0,628 & 0,003 & --- \\
\hline & PIB (\% de crescimento anual) & 0,317 & 0,002 & --- \\
\hline \multirow{3}{*}{ França } & Investimento em Defesa (\% do PIB) & 0,168 & 0,002 & --- \\
\hline & Formação Bruta de Capital Fixo (\% do PIB) & 0,381 & 0,001 & --- \\
\hline & PIB (\% de crescimento anual) & 0,014 & --- & --- \\
\hline \multirow{3}{*}{$\begin{array}{l}\text { Reino } \\
\text { Unido }\end{array}$} & Investimento em Defesa (\% do PIB) & 0,288 & 0,207 & 0,001 \\
\hline & Formação Bruta de Capital Fixo (\% do PIB) & 0,292 & 0,000 & --- \\
\hline & PIB (\% de crescimento anual) & 0,023 & --- & --- \\
\hline \multirow{3}{*}{ Rússia } & Investimento em Defesa (\% do PIB) & 0,089 & 0,000 & --- \\
\hline & Formação Bruta de Capital Fixo (\% of PIB) & 0,005 & --- & --- \\
\hline & PIB (\% de crescimento anual) & 0,038 & --- & --- \\
\hline \multirow{3}{*}{$\begin{array}{l}\text { Estados } \\
\text { Unidos }\end{array}$} & Investimento em Defesa (\% do PIB) & 0,018 & --- & --- \\
\hline & Formação Bruta de Capital Fixo (\% do PIB) & 0,179 & 0,013 & --- \\
\hline & PIB (\% de crescimento anual) & 0,065 & 0,000 & --- \\
\hline
\end{tabular}

Nota: Dados de 1992 a 2017. Software E-Views, versão 11.

Para os pares de séries "Investimento em Defesa e FBCF” do Brasil e da França foi testado se havia cointegração, pois elas são integradas de mesma ordem. Porém, a hipótese nula de que as séries não são cointegradas não foi rejeitada para os dois países, ao nível de significância de $5 \%$, com base no teste de cointegração de Johansen (valor- $p=0,095$ e valor$p=0,1233$, respectivamente).

Como o teste de causalidade de Granger é sensível ao número de lags selecionados, 
realizamos a análise variando de 1 a 7 lags, pois foi o número máximo possível de lags. Nas tabelas a seguir (Tabela 2 a Tabela 5) são apresentados os resultados do teste de causalidade de Granger para cada hipótese deste estudo $-\mathrm{H}_{1}$ a $\mathrm{H}_{4}$, e para cada um dos países analisados.

Tabela 2. Resultado (valor-p) do teste de causalidade de Granger $\left(\mathrm{H}_{0}\right.$ : Investimento em Defesa não Granger-causa o PIB; $\mathrm{H}_{1}$ : Investimento em Defesa Granger-causa o PIB), por número de lags e país.

\begin{tabular}{lllccccc}
\hline & \multicolumn{7}{c}{ lags } \\
\cline { 2 - 8 } & \multicolumn{1}{c}{1} & \multicolumn{1}{c}{2} & 3 & 4 & 5 & 6 & 7 \\
\hline Brasil & 0,8892 & 0,7977 & 0,9691 & 0,9454 & 0,9337 & 0,9808 & 0,9934 \\
China & $0,0577^{*}$ & $0,0165^{* *}$ & 0,1065 & 0,3063 & 0,3051 & 0,2647 & 0,4901 \\
França & 0,4337 & 0,5432 & 0,7717 & 0,8398 & 0,4959 & 0,6700 & 0,5731 \\
Reino Unido & 0,1926 & 0,3875 & 0,3737 & 0,2455 & 0,3976 & 0,1773 & 0,2420 \\
Rússia & 0,8028 & 0,6461 & 0,6327 & 0,7458 & 0,8430 & 0,9761 & 0,9895 \\
EUA & 0,2292 & 0,5753 & 0,5888 & 0,5425 & 0,7159 & 0,7476 & 0,7202 \\
\hline
\end{tabular}

Nota 1: Dados de 1992 a 2017. Software E-Views, versão 11.

Nota 2: *** valor- $p<0,01$; ** valor- $p<0,05$; * valor- $p<0,10$.

Tabela 3. Resultado (valor- $p$ ) do teste de causalidade de Granger $\left(\mathrm{H}_{0}\right.$ : PIB não Grangercausa Investimento em Defesa; $\mathrm{H}_{2}$ : PIB Granger-causa Investimento em Defesa), por número de lags e país.

\begin{tabular}{lllllccc}
\hline & \multicolumn{7}{c}{ lags } \\
\cline { 2 - 8 } & \multicolumn{1}{c}{1} & \multicolumn{1}{c}{2} & \multicolumn{1}{c}{3} & 4 & \multicolumn{1}{c}{5} & 6 & \multicolumn{1}{c}{7} \\
\hline Brasil & 0,5384 & 0,6666 & 0,4191 & 0,5698 & 0,7366 & 0,6393 & 0,7706 \\
China & 0,9893 & $0,0133^{* *}$ & $0,0411^{* *}$ & $0,0664^{*}$ & 0,1564 & 0,2436 & 0,4622 \\
França & 0,2288 & 0,1310 & 0,4910 & 0,5086 & 0,3333 & 0,4404 & 0,4269 \\
Reino Unido & $0,0204^{* *}$ & $0,0137^{* *}$ & $0,0574^{*}$ & $0,0881^{*}$ & 0,3466 & 0,5145 & 0,9044 \\
Rússia & 0,5633 & 0,1541 & 0,4697 & 0,5026 & 0,6142 & 0,8711 & 0,3747 \\
EUA & 0,3796 & 0,1064 & 0,2887 & 0,1797 & 0,3978 & 0,3925 & 0,4437 \\
\hline
\end{tabular}

Nota 1: Dados de 1992 a 2017. Software E-Views, versão 11.

Nota 2: *** valor- $p<0,01$; ** valor- $p<0,05$; * valor- $p<0,10$.

Tabela 4. Resultado (valor-p) do teste de causalidade de Granger $\left(\mathrm{H}_{0}\right.$ : Investimento em Defesa não Granger-causa Formação bruta de capital fixo; $\mathrm{H}_{3}$ : Investimento em Defesa Granger-causa Formação bruta de capital fixo), por número de lags e país.

\begin{tabular}{lllllccl}
\hline & \multicolumn{7}{c}{ lags } \\
\cline { 2 - 8 } & \multicolumn{1}{c}{1} & \multicolumn{1}{c}{2} & \multicolumn{1}{c}{3} & \multicolumn{1}{c}{4} & \multicolumn{1}{c}{5} & \multicolumn{1}{c}{6} & \multicolumn{1}{c}{7} \\
\hline Brasil & 0,8961 & 0,3371 & 0,9271 & 0,7781 & 0,7899 & 0,8965 & 0,3937 \\
China & $0,0595^{*}$ & 0,1230 & $0,0534^{*}$ & $0,0910^{*}$ & 0,2761 & 0,6783 & $0,0030^{* * *}$ \\
França & 0,6227 & 0,7917 & 0,8206 & 0,8703 & 0,6819 & 0,7465 & 0,6007 \\
Reino Unido & $0,0028^{* * *}$ & $0,0213^{* *}$ & $0,0285^{* *}$ & $0,0851^{*}$ & 0,1773 & 0,1997 & 0,2122 \\
Rússia & 0,3341 & 0,6053 & 0,6166 & 0,6817 & 0,7963 & 0,8072 & 0,9510 \\
EUA & 0,4674 & 0,7729 & 0,1755 & 0,2782 & 0,3664 & 0,3741 & 0,6199 \\
\hline
\end{tabular}

Nota 1: Dados de 1992 a 2017. Software E-Views, versão 11.

Nota 2: *** valor- $p<0,01$; ** valor- $p<0,05$; * valor- $p<0,10$. 
Tabela 5. Resultado (valor- $p$ ) do teste de causalidade de Granger $\left(\mathrm{H}_{0}\right.$ : Formação bruta de capital fixo não Granger-causa Investimento em Defesa; $\mathrm{H}_{4}$ : Formação bruta de capital fixo Granger-causa Investimento em Defesa), por número de lags e país.

\begin{tabular}{lllllccc}
\hline & \multicolumn{7}{c}{ lags } \\
\cline { 2 - 8 } & \multicolumn{1}{c}{1} & \multicolumn{1}{c}{2} & \multicolumn{1}{c}{3} & \multicolumn{1}{c}{4} & 5 & 6 & 7 \\
\hline Brasil & 0,3836 & 0,6409 & 0,6417 & 0,725 & 0,6905 & 0,9309 & 0,9259 \\
China & 0,2745 & 0,6422 & 0,8463 & 0,7122 & 0,7426 & 0,7536 & 0,3256 \\
França & 0,9607 & 0,2349 & 0,6266 & 0,6791 & 0,1979 & 0,6911 & 0,8141 \\
Reino Unido & 0,2440 & $0,0033^{* * *}$ & $0,0365^{* *}$ & 0,1505 & 0,2093 & 0,4453 & 0,7973 \\
Rússia & 0,9310 & 0,7861 & 0,7342 & 0,9057 & 0,9419 & 0,7347 & 0,9482 \\
EUA & $0,0029^{* * *}$ & 0,3622 & 0,1949 & $0,0818^{*}$ & 0,1017 & $0,0768^{*}$ & 0,1459 \\
\hline
\end{tabular}

Nota 1: Dados de 1992 a 2017. Software E-Views, versão 11.

Nota 2: *** valor- $p<0,01$; ** valor- $p<0,05$; * valor- $p<0,10$.

O resultado do teste de causalidade de Granger para o Brasil mostrou que o investimento em defesa não Granger-causa o PIB (ver Tabela 2), e nem o PIB Granger-causa o investimento em defesa (ver Tabela 3); da mesma forma, os testes indicaram que nenhuma relação causal foi identificada entre a formação bruta de capital fixo com o investimento em defesa (ver Tabelas 4 e 5).

No caso da China, os resultados indicaram uma bicausalidade, em que o investimento em defesa Granger-causa o PIB (valor- $p<0,05$; Tabela 2), e o PIB Grangercausa o investimento em defesa (valor- $p<0,05$; Tabela 3). Em relação ao investimento em defesa e à formação bruta de capital fixo, nota-se uma causalidade unilateral entre as variáveis, onde a formação bruta de capital fixo não Granger-causa o investimento em defesa (ver Tabela 5), mas investimento em defesa Granger-causa a formação bruta de capital fixo (valor- $p<0,01$; Tabela 4).

Em se tratando da França e da Rússia, os resultados mostraram que não há evidências de relação causal, no sentido de Granger, entre investimento em defesa e PIB (ver Tabelas 2 e 3), assim como entre investimento em defesa e formação bruta de capital fixo (ver Tabelas 4 e 5).

Para os EUA, o teste mostrou que a formação bruta de capital fixo Granger-causa investimento em defesa (valor- $p<0,01$; Tabela 5). Porém, todos os demais resultados mostraram independência entre as outras variáveis (ver Tabelas 2, 3 e 4).

Por fim, os testes envolvendo o Reino Unido indicaram que investimento em Defesa não Granger-causa o PIB (ver Tabela 2), mas o PIB Granger-causa Investimento em Defesa (valor- $p<0,05$; Tabela 3). Além disso, há uma bicausalidade entre investimento em defesa e formação bruta de capital fixo, na qual o investimento em defesa Granger-causa a formação bruta de capital fixo (valor- $p<0,01$; Tabela 4), e a formação bruta de capital fixo Granger-causa o investimento em defesa (valor- $p<0,01$; Tabela 5).

\section{CONSIDERAÇÕES FINAIS}

Este estudo apresentou uma análise do impacto do investimento em defesa na economia, com base no teste de causalidade de Granger. Para isso, foram utilizados os dados de investimento em defesa, PIB e formação bruta de capital fixo de seis países.

Dos países analisados, para cada uma das hipóteses deste estudo, a China e o Reino Unido foram os que mais apresentaram relação causal entre as variáveis (China - hipóteses confirmadas: H1, H2 e H3; Reino Unido - hipóteses confirmadas: H2, H3 e H4), seguidos dos EUA (apenas H4 confirmada). Ao observar o Gráfico 1, percebe-se que a China e o 
Reino Unido apresentaram, nos últimos cinco anos, um nível de investimento em defesa semelhante, entre $1,8 \%$ e $2 \%$ do PIB, ao mesmo tempo que os outros países tiveram nível de investimento em defesa muito acima disso, como Rússia e EUA, ou muito abaixo, como o Brasil. Essas observações sobre os níveis de investimento vão ao encontro da teoria da Função do Investimento e a Eficiência Marginal do Capital, que diz que para impactar diretamente no produto interno bruto é preciso ter cautela em não investir pouco nem investir em excesso, visando atingir o ponto de eficiência máxima (BRESSER-PEREIRA, 2016).

Recomenda-se um estudo futuro com outros países que tenham percentuais de investimento em defesa em relação ao PIB semelhantes aos da China e aos do Reino Unido, para que se possa confirmar se essa proporção de investimento adotada por esses países é a adequada para que haja relação de causalidade. Adicionalmente, o número de variáveis também pode ser acrescido, incluindo o total de importações e de exportações.

\section{REFERÊNCIAS BIBLIOGRÁFICAS}

[1] AL-YOUSIF, Y. K. Defense spending and economic growth: Some empirical evidence from the Arab Gulf Region. Defense and Peace Economics, Volume 13(3), pp. 187-197, 2002.

[2] ANDO, Shio. The impact of defense expenditure on economic growth: Panel data analysis based on the Feder Model. International Journal of Economic Policy Studies, v. 4, n. 1, p. 141-154, 2009.

[3] ANWAR, Muhammad Azfar; RAFIQUE, Zain; JOIYA, Salman Azam. Defense spending-economic growth nexus: A case study of Pakistan. Pakistan Economic and Social Review, p. 163-182, 2012.

[4] BRESSER-PEREIRA, Luiz Carlos. A Função do Investimento e a Eficiência Marginal do Capital. Disponível em http://www.bresserpereira.org.br/works/casos/73. $\quad$ Fun\%C3\% $\quad$ A7\% $\%$ 3 \%A3oInvestimento_EficienciaMarginalDoCapital.pdf. Acesso em 20 jan.2016.

[5] CARNEIRO, Francisco Galrão. A metodologia dos testes de causalidade em economia. Brasília: Departamento de Economia, Universidade de Brasília. Texto didático, 1997.

[6] DICKEY, David A.; FULLER, Wayne A. Distribution of the estimators for autoregressive time series with a unit root. Journal of the American statistical association, v. 74, n. 366a, p. 427-431, 1979.

[7] DICKEY, David A.; FULLER, Wayne A. Likelihood ratio statistics for autoregressive time series with a unit root. Econometrica: Journal of the Econometric Society, p. 1057-1072, 1981.

[8] GOKMENOGLU, Korhan K.; TASPINAR, Nigar; SADEGHIEH, Mohammadesmaeil. Military expenditure and economic growth: The case of Turkey. Procedia Economics and Finance, v. 25, p. 455-462, 2015.

[9] GRANGER, Clive WJ. Investigating causal relations by econometric models and cross-spectral methods. Econometrica: Journal of the Econometric Society, p. 424438, 1969.

[10] HOBBES, Thomas. Leviatã [1651]. São Paulo. Coleção Os Pensadores, 1974.

[11] HOBBES, Thomas. Natureza Humana [1650]. Lisboa: Imprensa Nacional Casa da Moeda, 1983. 
[12] HOBBES, Thomas. Do Cidadão [1642]. São Paulo: Martin Claret, p. 286, 2004.

[13] HOBBES, Thomas. De Corpore [1655]. Hoboken: Wiley-Blackwell, 2005.

[14] KEYNES, John Maynard. The general theory of employment, interest, and money. Springer, 2018.

[15] MANKIW, N. Gregory. Introdução à economia. Cengage Learning, 2008.

[16] MAQUIAVEL, Nicolau. Discorsi: Comentários Sobre a Primeira Década de Tito Lívio [1531]. Brasília: Universidade de Brasília, 1994.

[17] MAQUIAVEL, Nicolau. O Príncipe [1532]. 2a Edição. Clio Editora, 2012.

[18] STANFORD ENCYCLOPEDIA OF PHILOSOPHY. Hobbes's Moral and Political Philosophy. Disponível em http://plato.stanford.edu/entries/hobbes-moral/. Acesso em 24 dez.2015.

[19] STOCKHOLM INTERNATIONAL PEACE RESEARCH INSTITUTE. SIPRI Military Expenditure Database. Disponível em https://sipri.org/sites/default /files/2019-04/fs 1904 milex 2018 0.pdf. Acesso em 12 mai.2019.

[20] TAHIR, Rizwan; SAJID, G. Defence spending and economic growth in less developed countries: Re-examining the issue of causality. Government College Economic Journal, Volume 32(1\&2), pp. 27-39, 1999.

[21] TAMBUDZAI, Z. Military Burden Determinants in Southern Africa, 1996-2005: A Cross-section and Panel Data Analysis. Economic Development in Africa Conference. Oxford: St Catherine's College, 2007.

[22] THE WORLD BANK. World Bank national accounts data, and OECD National Accounts data files. Disponível em https://data.worldbank.org/indicator/NY.GDP. MKTP.CD?year high desc=true. Acesso em 01 mai.2019.

[23] VON CLAUSEWITZ, Carl. Da guerra [1832]. WWF Martins Fontes, 2017.

[24] WANG, Tung-Pao; SHYU, Stacy Huey-Pyng; CHOU, Han-Chung. The impact of defense expenditure on economic productivity in OECD countries. Economic Modelling, v. 29, n. 6, p. 2104-2114, 2012. 